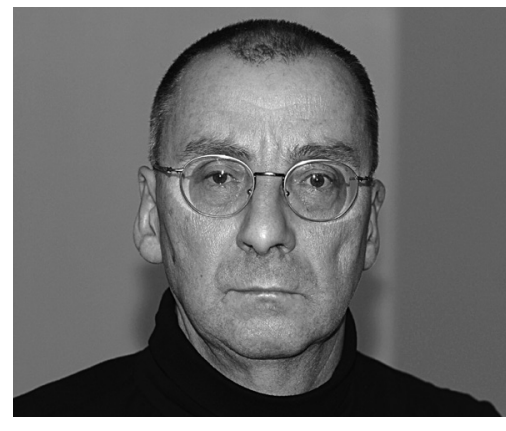

\title{
Wirkungen und Nebenwirkungen
}

Entscheidend sei, was hinten rauskomme, hat einmal ein Bundeskanzler festgestellt. Vergessen wird bei einer solchen Haltung oft, dass man für die Bewertung von Ergebnissen zunächst wissen muss, was man eigentlich erreichen will. Zuerst gilt es also die Ziele festzulegen, danach die Ressourcen und Methoden zu bemessen und dann die erhofften Wirkungen zu kontrollieren. Soweit die Theorie. Es sei das ganze Wesen und die Würde der Menschen, dass wir in sozialen Dingen tatsächlich erst die Kur finden müssten, ehe wir die Krankheit fänden, konstatiert pragmatisch der englische Schriftsteller Gilbert Keith Chesterton. Der für die Sozialwirtschaft entwickelte Ansatz des Social Return on Investment versucht einen für Politik und Unternehmen gangbaren Weg zur Wirkungsmessung aufzuzeigen, wie Britta Wagner von der Beratungsfirma xit forschen. planen. beraten in ihrem Beitrag am Beispiel der Eingliederungshilfe erläutert. Mit diesem differenzierten Instrumentarium sollen zum einen die Mittelströme in der Finanzierung und die Wirkungen sozialer Dienstleistungen sichtbar gemacht werden und zum anderen begründet darüber spekuliert werden, welche Kosten und Erträgen durch alternative Vorgehensweisen entstünden. Berücksichtigt werden dabei negative Nebeneffekte »eigentlich « richtiger Maßnahmen; etwa wenn eine Werkstatt für behinderte Menschen ihre behinderten Mitarbeitenden tatsächlich in den Arbeitsmarkt vermittelt, ihr dann aber die Leistungsstärkeren fehlen, um einen wirtschaftlichen Betrieb aufrechtzuerhalten. Michael Macsenaere zählt in seinem Beitrag einige in der Jugendhilfe entwickelte Methoden zur Wirkungsmessung in der Praxis auf, die durchaus auch für andere Arbeitsfelder der Sozialwirtschaft infrage kommen können. 